\title{
Pathological changes waterproof membranes and their identification
}

\author{
Marek Novotný ${ }^{1, *}$ and Ivan Misar ${ }^{2}$ \\ ${ }^{1}$ Faculty of Architecture, Czech Technical University, Thákurova 9, 16900 Prague 6, Czech Republic \\ ${ }^{2}$ A.W.A.L.,s.r.o., Eliášova 20, 16000 Prague 6, Czech Republic
}

\begin{abstract}
With the development of waterproofing systems based on synthetic membranes, especially $\mathrm{mPVC}$, there is an increase in pathological changes of these membranes. Competing manufacturers and pressure on price of the final product have resulted in usage of unstable or low quality raw materials. After production, these materials keep their specific characteristics, however, their aging is accelerated, i.e. they lose their essential qualitative characteristics very quickly. Very important is the detection of these processes which is possible using chemical analysis (gas chromatography, IR analysis and others) as well as using visual inspection of surface by microscope, including 3D modeling. Very important are weldability tests which identify glass transition temperature of the material. The results can then be used as a basis for correct identification of problems with weldability, nonweldability of synthetic membranes, respectively, as well as for identification of normal or abnormal aging of these materials.
\end{abstract}

\section{Introduction}

The price war has already broken out in the building industry. Waterproofing materials based on plasticized PVC, shortly $\mathrm{mPVC}$, are no exception. The polyvinylchloride (PVC) is a rigid polymer which must be mixed with the plasticizing agents. The mPVC foil is produced by a mix of polyvinylchloride, plasticizers, stabilizers and other admixtures [1]. The investors are ultimate victims, who must deal with complaints, and reduced durability of waterproofing materials, especially in roof constructions. This situation does not only concern to foil waterproofing materials, but also waterproofing materials base on asphalt.

The foils of $\mathrm{mPVC}$ as a significant part of the insulation system in large hall buildings are currently the dominant technical solution. For that reason, the manufacturers will focus on this specific type of waterproofing material. The price is the major key to success. It is necessary to emphasize; the price has a direct relationship on the durability of the material.

The problem of shortened durability does not arise immediately after its production, but after incorporation into the building constructions. This condition is characterized as accelerated aging of waterproofing materials of mPVC type. This phenomenon is caused by

\footnotetext{
*Corresponding author: novotny@awal.cz
} 
migration of plasticizers from film material. Aging does not have a linear character. The aging is accelerated with respect to increasing surface of evaporation (Figure 12).

\section{Materials testing}

The consequences are a reduction in frictional resistance against any stress of material, respectively flexibility, at low temperatures, a related tests filler content, respectively material thickness in cross-section. The aging decreases due to the content of plasticizers, thus it is increasing the proportion of fillers, which are not lost, respectively reduction of thickness because plasticizers are diminishing. All causes are documented [2-4] and confirmed by bend testing of material (film mPVC) in cold conditions, within which cracks are visually searched. An example is in the following paragraph.

Ranges of cracks in the surface of the test sample at various temperatures of test were determined during the testing. The results are summarized in Table 1.

Table 1. Bend testing of material at low temperatures.

\begin{tabular}{|c|c|c|}
\hline The test sample & Temperature $\left[{ }^{\circ} \mathrm{C}\right]$ & The upper surface - cross $[-]$ \\
\hline 1 & 23 & 0 - crack (slightly) \\
\hline 2 & 15 & 2 - larger cracks \\
\hline 3 & 5 & 3 - the sample cracked across the width or fragmented \\
\hline 4 & 0 & 3 - the sample cracked across the width or fragmented \\
\hline 5 & -5 & 3 - the sample cracked across the width or fragmented \\
\hline
\end{tabular}

The performed measurements show that the waterproofing membrane does not perform its function after a very short time (approximately 6 years after incorporation into the construction in 2010). As it is apparent from the results of the bending of sample, the cracking occurs at temperatures around $15{ }^{\circ} \mathrm{C}$. There is a strong cracking waterproof material over the entire width at low temperatures of about $0{ }^{\circ} \mathrm{C}$. The condition of the waterproofing sheet of material can be documented by a variety of analytical methods such as IR, gas chromatography, and other.

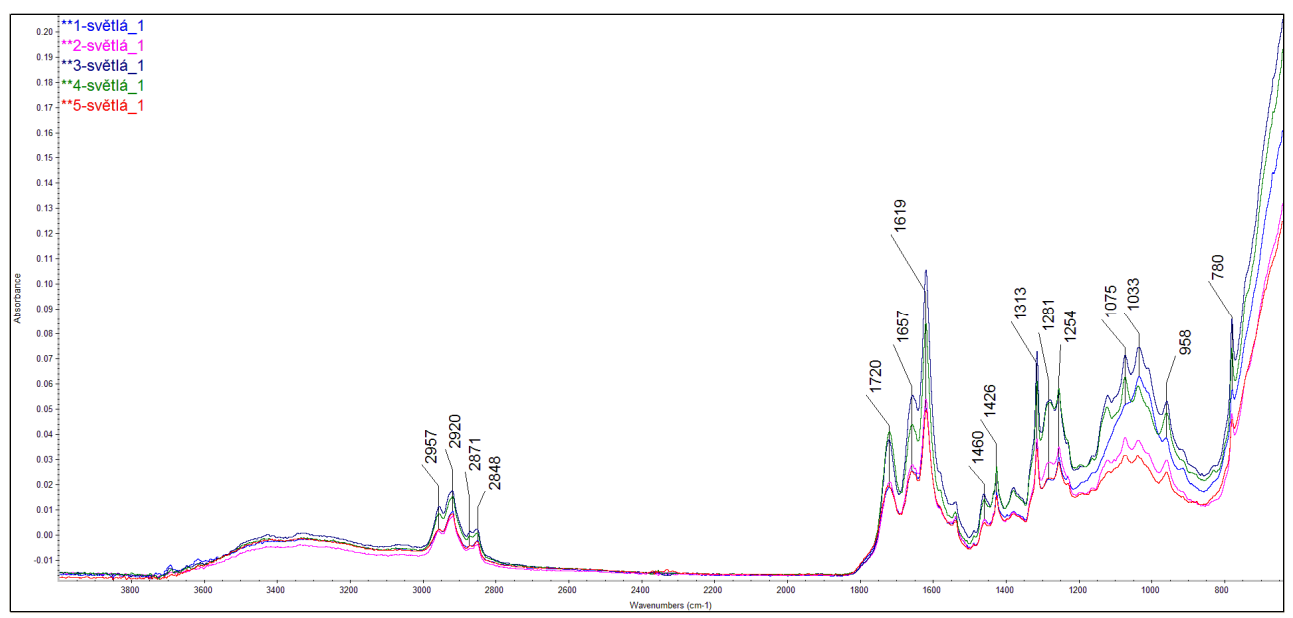

Fig. 1. Documentation of changes in mass of mPVC between covered and uncovered material. 


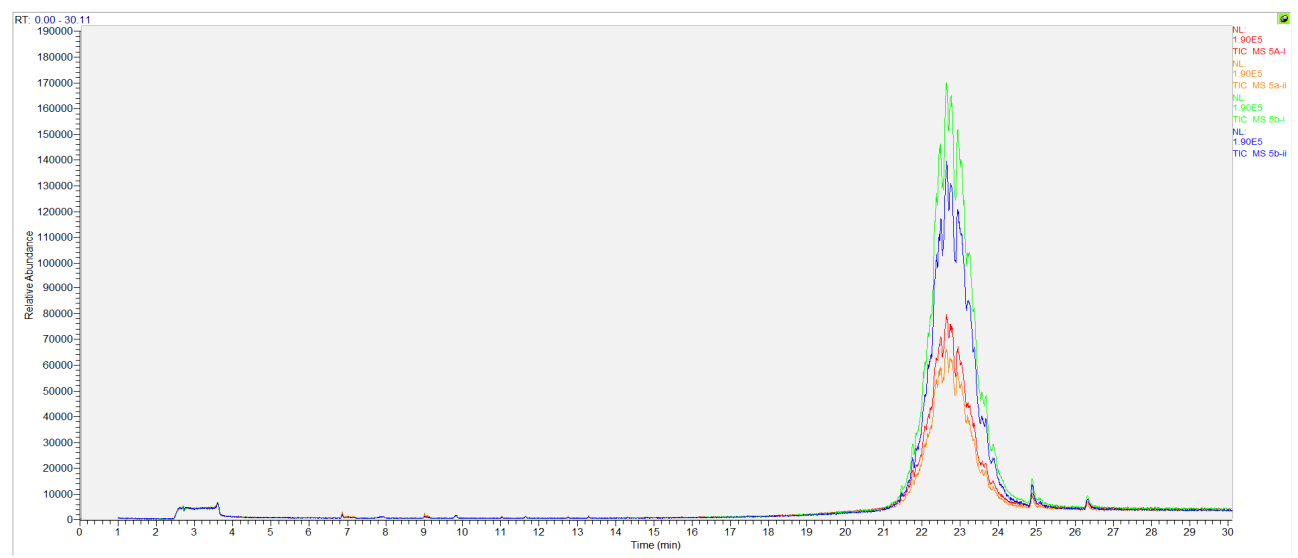

Fig. 2. Documentation of softeners and their comparison between covered and uncovered material.

Using these two methods, it is possible to obtain information on whether there were changes in the structure of the waterproofing material (IR analysis) and can be identified the pathological changes of the plasticizer. However, these processes cannot be precisely quantified. The using gas chromatography (English Gas chromatography, GC abbreviation) can cause loss of plasticizers and quantified.

These analytical methods in combination with the use of microscopic technology allow to identify defects and subsequently determined the remaining useful life, if there exists. It is possible to identify further possible manufacturing defects and their consequences apart from visual evidence of migration of plasticizers.

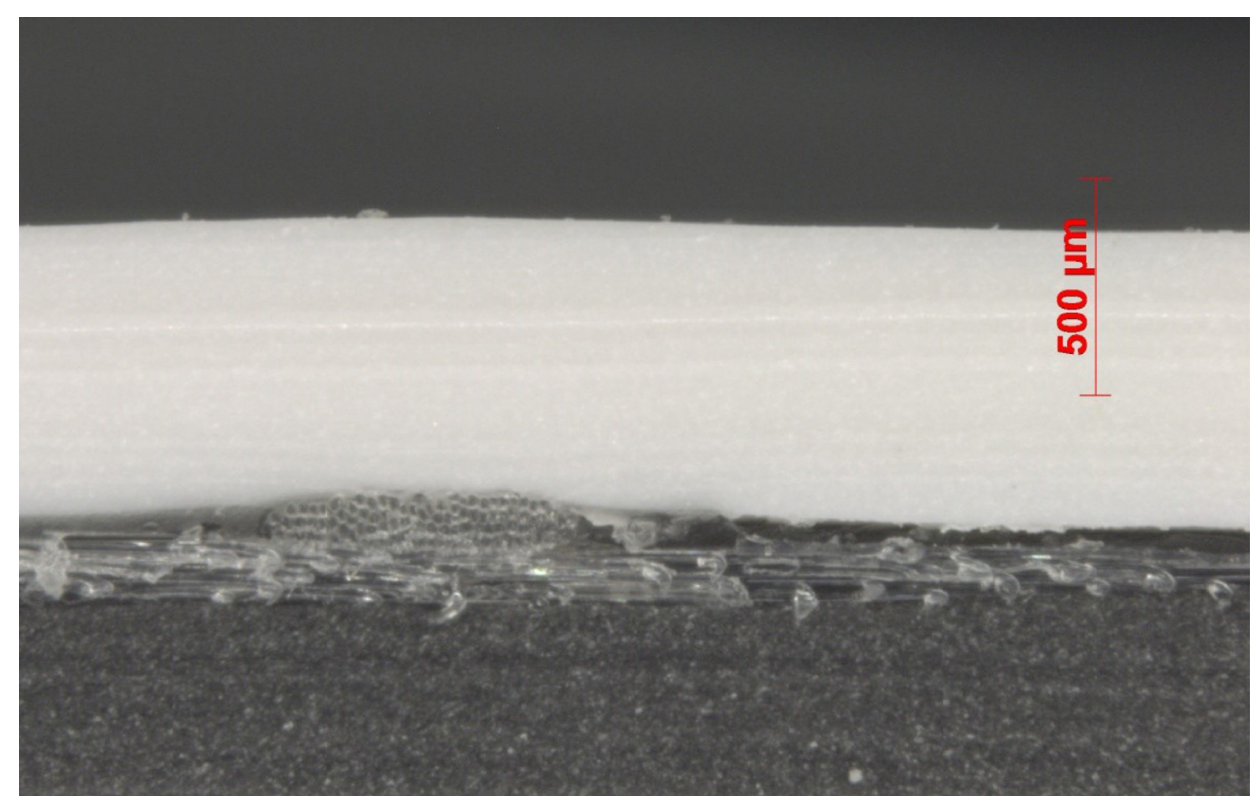

Fig. 3. The optimal condition of mPVC foil. 


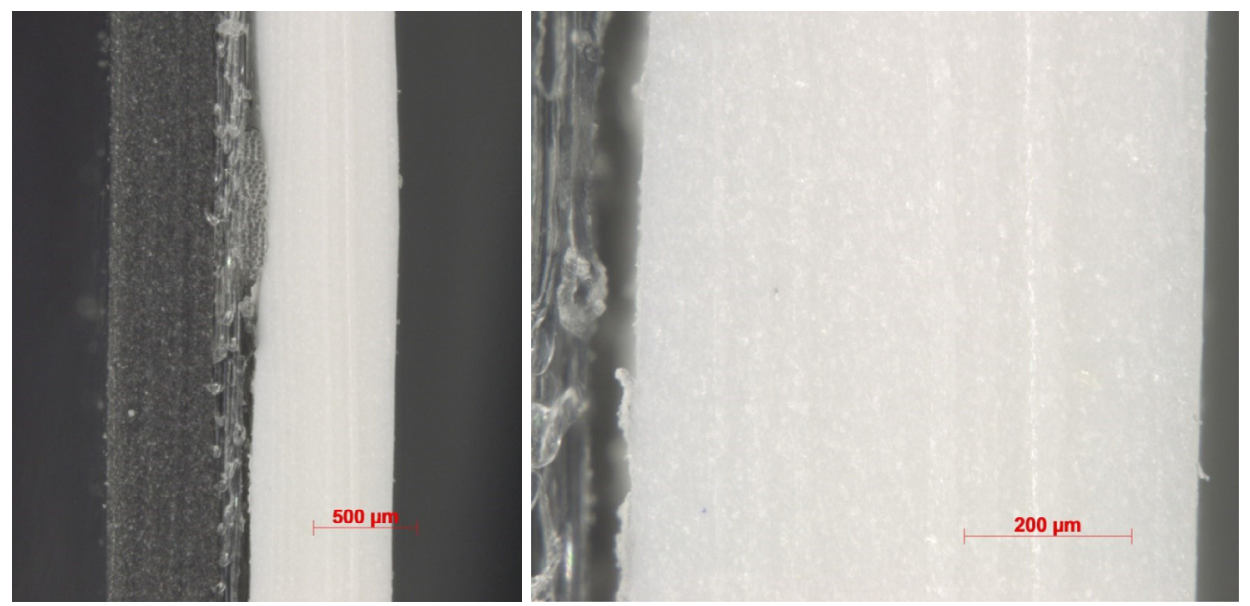

Fig. 4. Higher magnification shows inhomogeneity of the mPVC foil - The absorbency of humidity is the consequence of this inhomogeneity.

The following figures show the consequence.

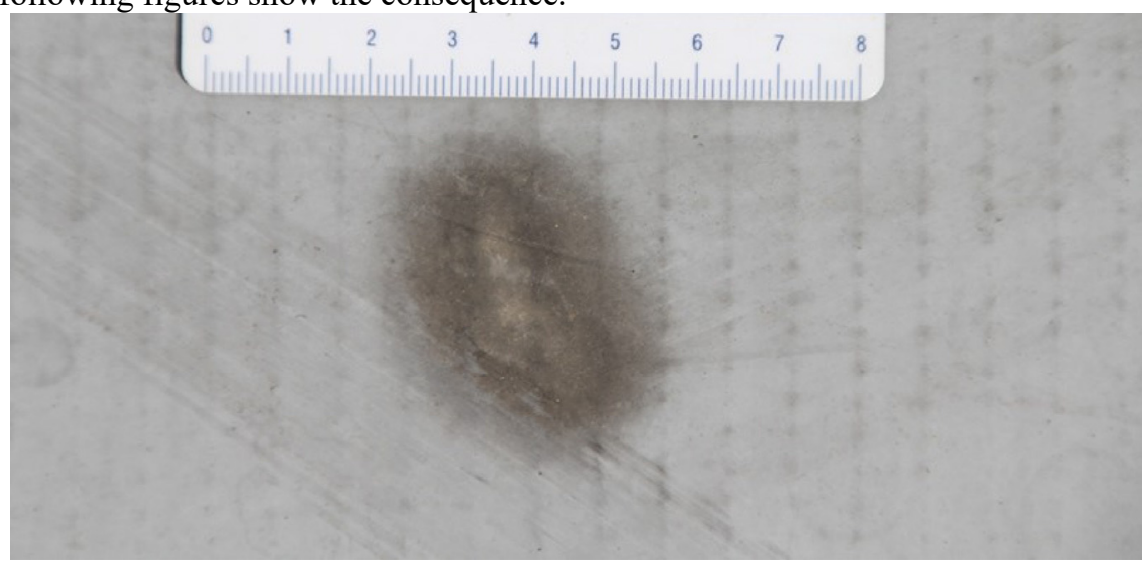

Fig. 5. Degradation spots on PVC foil.

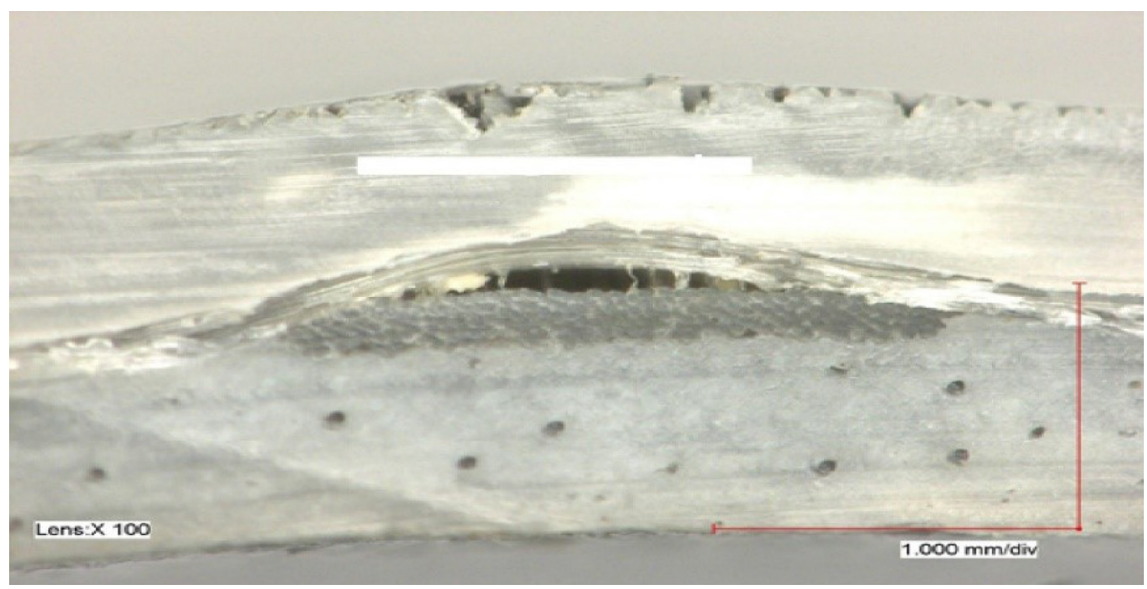

Fig. 6. Degradation blisters on the foil mPVC. 


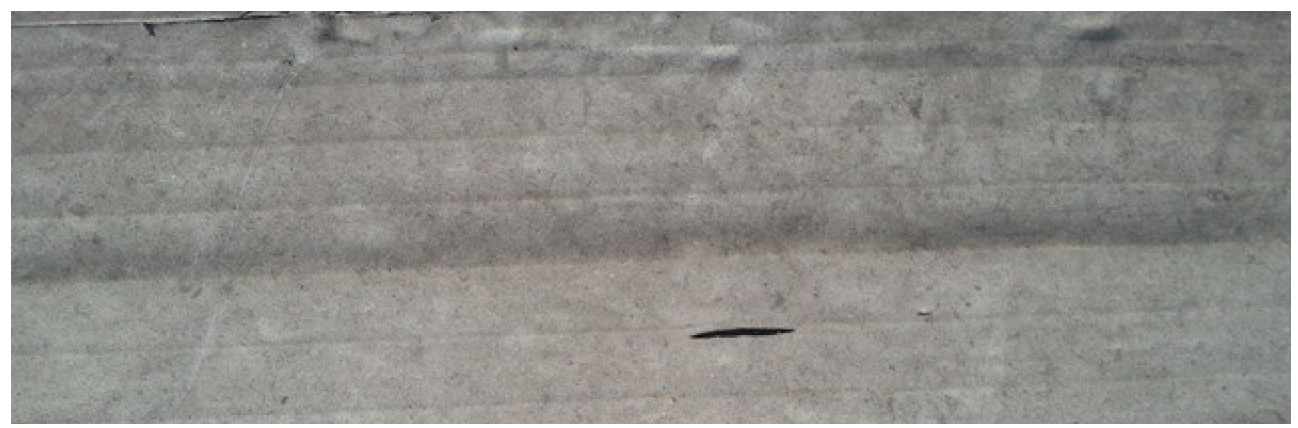

Fig. 7. The crack in mPVC foil.

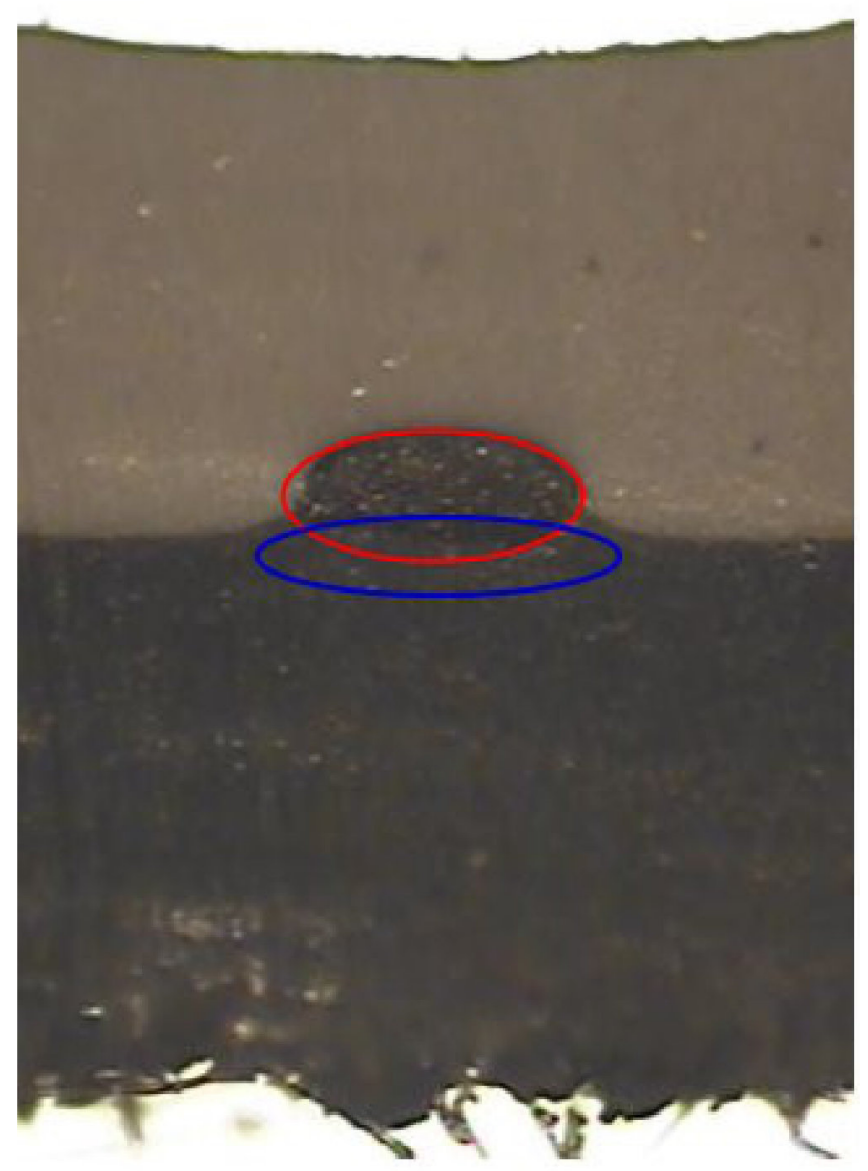

Fig . 8. Notch, weakening on the top of the PVC foil. At the correct position of the reinforcement should be in the shape of the bottom (blue) oval. 


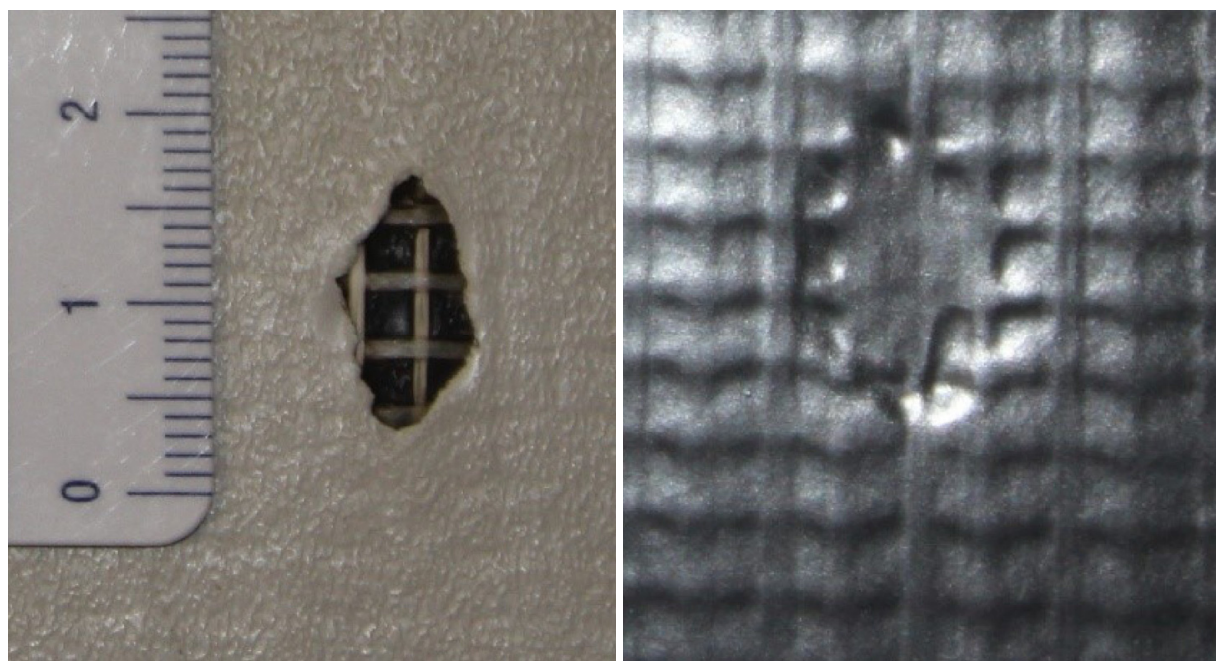

Fig. 9. Broken lower and upper surface of the mPVC foil.

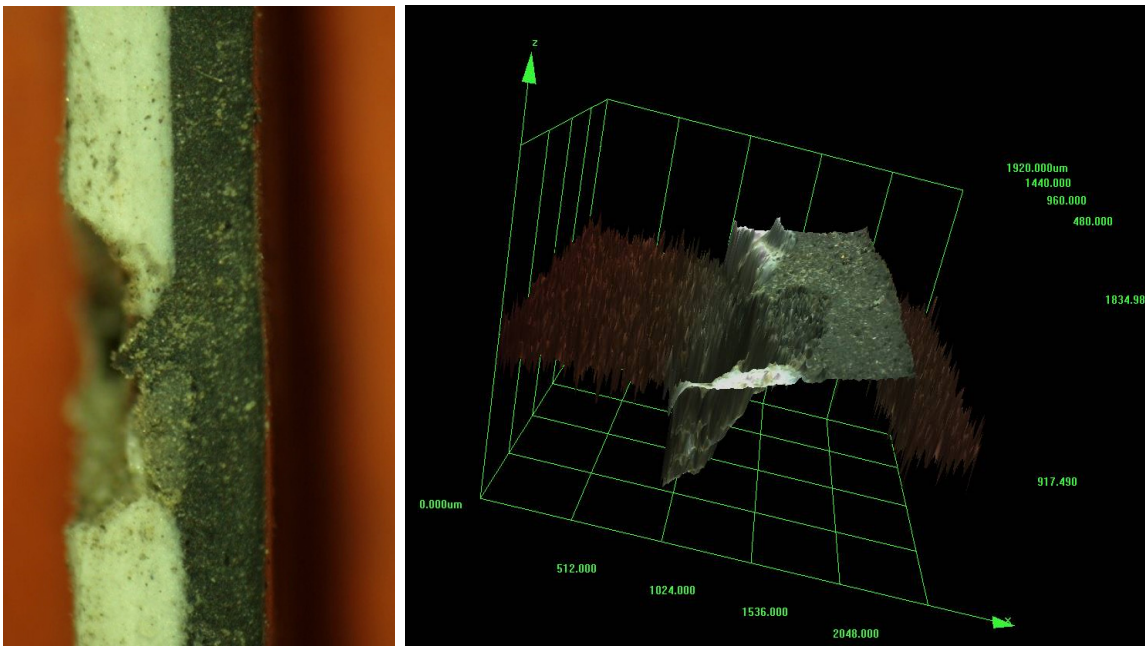

Fig. 10. Macro violations (left) and 3D modelling (right) of the violation by the mPVC foil.
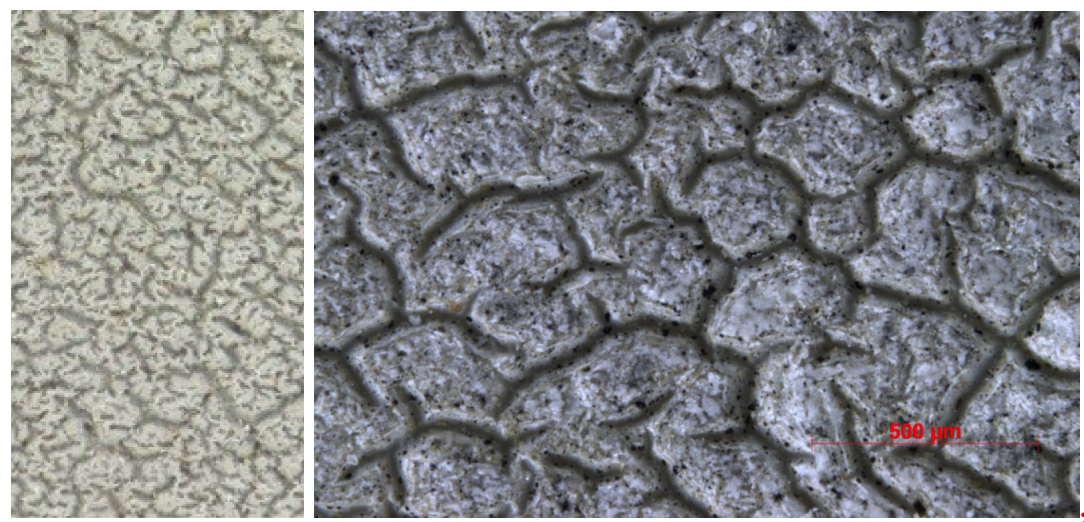

Fig. 11. Documentation "alligator ring" on the surface of the foil degrading mPVC and lower magnification (camera) on left side and micrograph of the surface on the right side. 


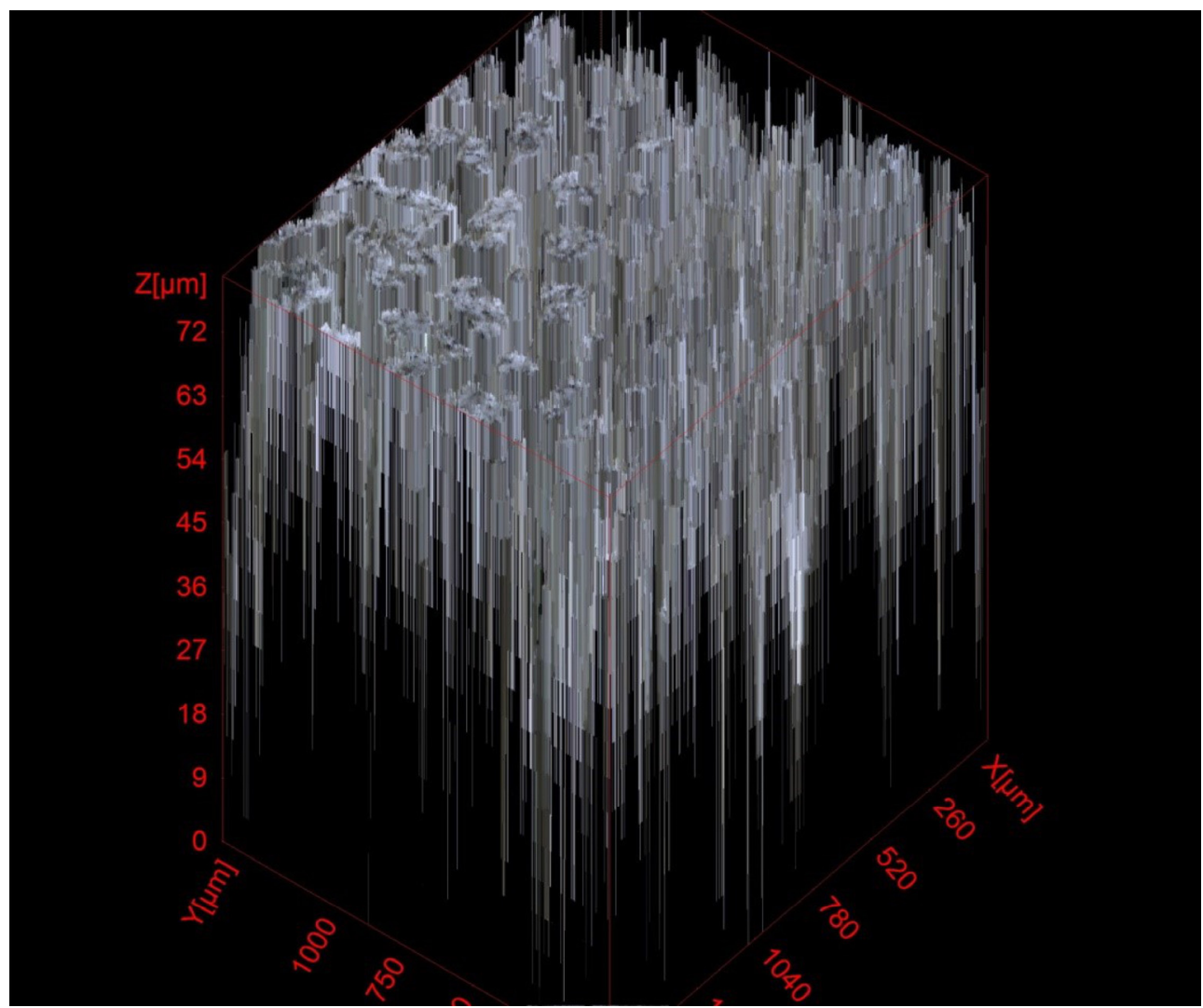

Fig. 12. Documentation of vaporizing surface of $\mathrm{mPVC}$ foil obtained from alligator ring, see fig. 11.
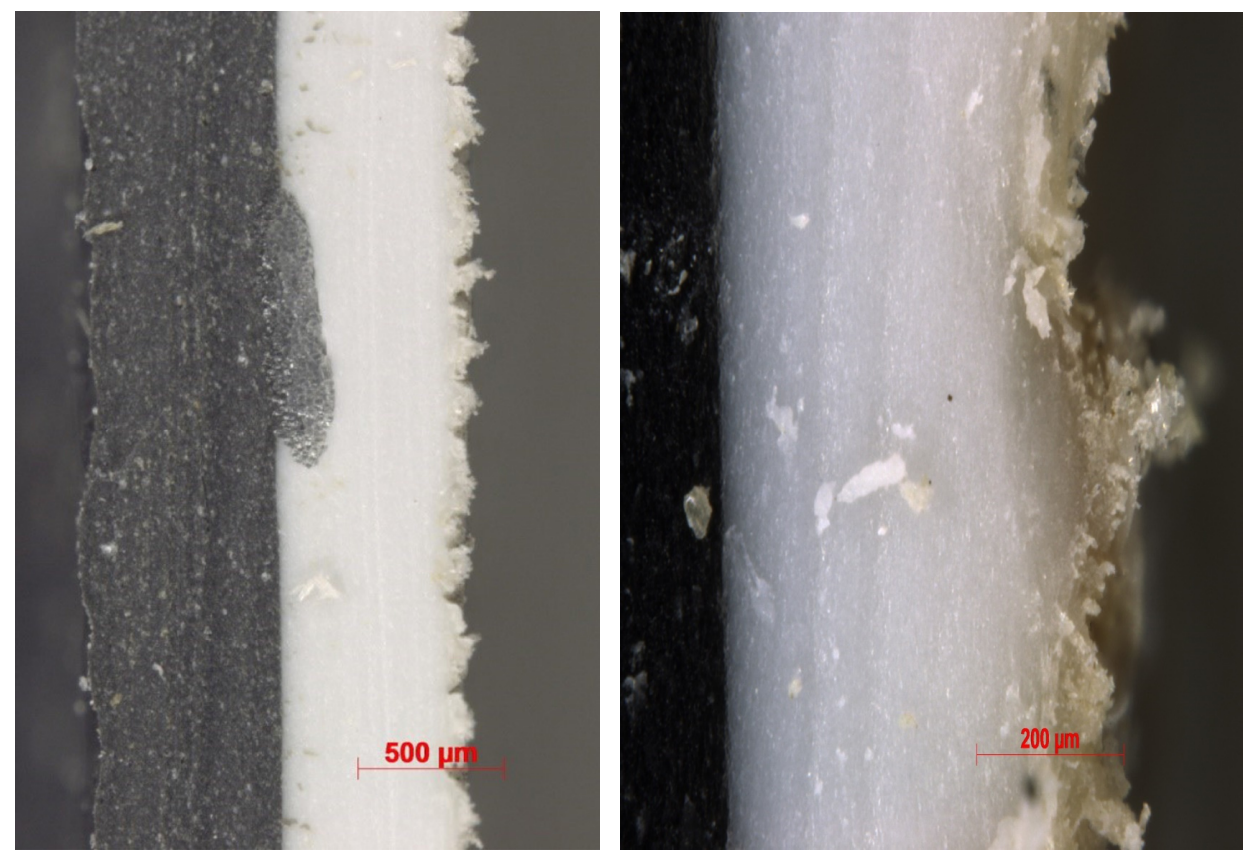

Fig. 13. Degradation of $\mathrm{mPVC}$ surface of the foil including a bad position of reinforcement. 
Figure 13 illustrates degradation of the surface of the waterproofing membrane. It is a visible reduction in the volume of plasticizers. Figure 14 shows the state just before the collapse or collapse of the film.

The bursting of upper layers mPVC film is caused by forcefully stress. The overall loss of waterproof characteristics of waterproofing membrane is consequence of the rupture.

The figure 14 illustrates clearly visible crack in the top portion of the film that there are caused by the force stress of the film during its lifetime.

It is important to note that the total lifetime of the film is only 6 years old (Figure 1-4, 11-14). The durability is does not match the investor needs as well as the lifetime does not correspond with the EU standards and technical reports. According to the EOTA 002 $(12 / 1999)$, the expected lifetime is at least 25 years.
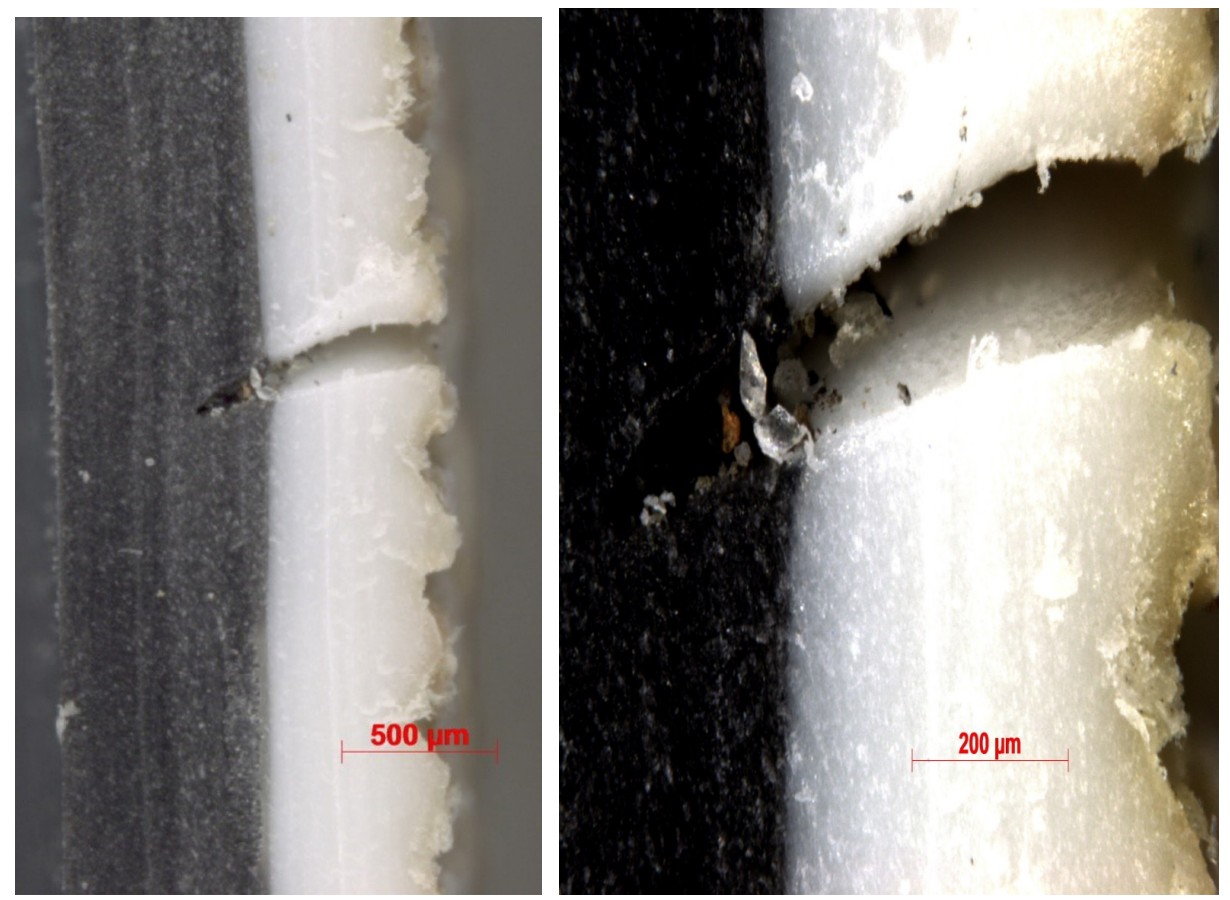

Fig. 14. Definitive end of functionality of PVC foil (waterproofing membrane) as a result of rupture.

\section{Conclusion}

The presented results are taken from executed expertise against specific manufacturers and specific material. It is necessary to say that the presented results are obtained by observing the cheapest type of $\mathrm{mPVC}$ foil on the Czech market. With respect to the occurring serious problems, it is recommended to stop the further production.

\section{References}

1. G.M. Vinhas, R.M. Souto-Maior, C.M. Lapa, Y.M. Bastos de Almeida, Mat. Res., 6 (4) (2003)

2. M. Novotný, Technical documentation, private database - expert witness (Unpublished) 
3. FA CTU, Faculty of Engineering, Technical University of Liberec - technical documentation, test reports (Unpublished)

4. A.W.A.L., Technical documentation (Unpublished) 